\title{
COMPARISON OF EMERGENCY SURGERIES UNDER SPINAL ANESTHESIA IN COVID-19 PANDEMIC WITH PRE-COVID PERIOD IN A TERTIARY CARE HOSPITAL OF A DEVELOPING COUNTRY
}

\author{
Sanum Kashif, Taimur Azam Khan*, Naheed Parveen ${ }^{* *}$, Najm Us Saqib Khan***, Saad Ahmed**** \\ Frontier Corps Hospital, Quetta Pakistan, *63 Medical Battalion, Multan Pakistan, **University of Medical and Health Sciences, Jamshora Pakistan, \\ ${ }^{* * *}$ Bahria University Medical and Dental College, Karachi Pakistan, ${ }^{* * *}$ Isolation Hospital and Infections Treatment Center, Islamabad Pakistan
}

\section{ABSTRACT}

Objective: To compare emergency surgeries under spinal anesthesia in COVID-19 pandemic with pre-COVID period in a tertiary care hospital of a developing country.

Study Design: Prospective observational study.

Place and Duration of Study: Main Operation Theatre, Frontier Corps Hospital Quetta, from Mar to May 2020.

Methodology: All emergency surgeries done under Spinal Anesthesia, were compared to emergency cases done in the preCOVID period. Anesthesia notes were reviewed. Emergency cases done under general anesthesia and personal protective equipment worn were also noted. Ages of the patients were from 18-75 years. Spinal anesthesia was performed by consultant anesthesiologist.

Result: Among total cases, 260 emergency cases were performed in the main operation theatre during the 3 months of preCOVID period as compared to only 89 cases in the 3 months duration of COVID-19. Spinal anesthesia was used in 154 (59.2\%) cases in the pre-COVID study period, while in COVID-19 pandemic 77 (86.5\%) emergency cases were performed under spinal anesthesia.

Conclusion: Spinal anesthesia has a significant role in the surgical management of patients in pre-COVID and especially in COVID pandemic. It provides high-quality perioperative care for patients whilst minimizing exposure to staff and utilization of scarce resources of personal protective equipment.

Keywords: COVID-19, Emergency surgery, Regional anesthesia, Spinal anesthesia, Tertiary care hospital.

\footnotetext{
This is an Open Access article distributed under the terms of the Creative Commons Attribution License (https://creativecommons.org/licenses/by-nc/4.0/), which permits unrestricted use, distribution, and reproduction in any medium, provided the original work is properly cited.
}

\section{INTRODUCTION}

Regional anesthesia has a pivotal role in surgical interventions as far as safety is concerned e.g. in obstetrics; regional anesthesia is beneficial for both mother and baby ${ }^{1}$. Spinal anesthesia plays an important role in surgical management of suspected or confirmed COVID-19 cases. As far as Regional anesthesia is concerned, it enhances overall recovery after surgery. In perspective of COVID-19, it reduces contamination of operation theatre and related staff, by decreasing potential risky interventions and therefore increases the efficiency of operation theatre. Patients also get safe and effective anesthesia with less post op complication as compare to general anesthesia ${ }^{2}$.

General anesthesia involves high risk aerosolgenerating interventions e.g. ventilation, tracheal intubation and suctioning, that put operation theatre team at risk ${ }^{3,4}$. It also increases the risk of post operative complications due to limited respiratory reserves of COVID patients. Tracheal intubation has been highlighted as a high-risk aerosol-generating procedure,

Correspondence: Dr Sanum Kashif, Department of Anaesthesia, Frontier Crops Hospital, Quetta Pakistan

Received: 19 Mar 2021; revised received: 20 Apr 2021; accepted: 02 Jul 2021 with an of transmission of 6.6 for SARS-CoV-1 when compared with unexposed healthcare workers ${ }^{5}$. However, the incidence of infection in healthcare workers involved in tracheal intubation of suspected or confirmed COVID-19 is unknown, and it is unclear which elements of the procedure may contribute to increased risk, if any. General anesthesia also involves more baseline personal protective equipment (PPE) use, which causes early depletion due to limited resources ${ }^{6}$.

Emergency procedures usually come from obstetrics, general surgery and orthopedics side, both in pre COVID and during COVID-19 pandemic. Despite of significant reduction in elective cases during COVID19 , emergency surgeries have not reduced much and practice changed accordingly7. During COVID-19 pandemic, emergency surgical patients usually treated as "COVID-19 suspected"; therefore, for aerosol generating procedures (AGP), PPE (fluid-resistant gown, gloves, visor and FFP3 respirators or PAPR hoods) is used. Aerosol-generating procedures include, tracheal intubation, tracheostomy, broncho-scopy non- invasive ventilation, cardiopulmonary resuscitation, manual ventilation). Health care providers should use eye protection, gloves and gowns and respirators. According to literature, tracheal intubation during general anes- 
thesia is among the high-risk situations where full PPE is required for surgery due to potential COVID-19 exposure and found an absolute risk increase of between $10 \%$ (cohort studies) and 15\% (case-control studies) for transmission of SARS-CoV-1-associated infection to health care personnel performing intubation ${ }^{8,9}$. For donning and doffing of PPE must follow standard guidelines, especially during emergency procedures, where the risk of getting infection of surgical staff are higher. The possible exposure to SARS-CoV-2 viral particles during aerosol-generating procedures is a potential risk to surgical staff ${ }^{10}$. In the current study, we compared the use of spinal anesthesia for emergency surgeries in pre COVID period versus COVID-19 pandemic.

\section{METHODOLOGY}

This prospective observational study was conducted at Anesthesia department of Frontier Corps Hospital Quetta, from March to May 2020. All patients of 1875 years requiring emergency surgery over the defined study period were included by non-probability consecutive sampling technique, with the exception of pediatric population and compared to emergency cases done in corresponding timeframe in 2019. Anesthesia notes were reviewed in detail to ascertain the perioperative use of spinal anesthesia. Emergency cases done under general anesthesia were also noted. Spinal anesthesia was performed by consultant anesthesiologist. All cases under spinal anesthesia were performed using aseptic technique, with PPE, recommended for AGP, were used. Results were analyzed by using SPSS16. Percentages and frequencies were calculated for categorical variables like surgical specialty, type of anesthesia and type of emergency procedures. The chi square test was used for comparison of emergency cases according to anesthesia.

\section{RESULTS}

A total of 260 emergency cases of three specialties i.e. General Surgery, Gynaecology \& Orthopedics were performed in the main operation theatre during the 3 months of pre-COVID period as compare to only 89 cases in the 3 months duration of COVID-19 (table-I).

In the pre-COVID study period, spinal anesthesia was used as an anesthetic technique in 154 (59.2\%) cases while general anesthesia was used in 106 (40.7\%) while in COVID-19 pandemic 77 (86.5\%) emergency cases were performed under spinal anesthesia and $12(13.4 \%)$ under general anesthesia, $p$-value $<0.001$ (table-II) (figure).

Among different specialties, emergency cases in general surgery, during COVID-19 period were mainly appendectomies 15 (65.2\%), in Gynaecology, main emergency cases were lower segment caesarean section $37(86 \%)$ and in orthopedics, main emergency cases were $11(47.8 \%)$ open reduction and internal fixation of femur (table-III).

Table-I: Comparison of surgeries in pre-COVID and COVID pandemic.

\begin{tabular}{l|c|c|c}
\hline Specialty & March-May 2019 & March-May 2020 \\
\hline General surgery & $180(69.2 \%)$ & $23(25.8 \%)$ \\
\hline Gynaecology & $50(19.2 \%)$ & $43(48.3 \%)$ \\
\hline Orthopedics & $30(11.5 \%)$ & $23(25.8 \%)$ \\
\hline Total & 260 & \multicolumn{2}{c}{89} \\
\hline $\begin{array}{l}\text { Table-II: Comparison of emergency spinal versus general } \\
\text { anesthesia cases. }\end{array}$ & $\begin{array}{c}\text { Cases: SA/GA- } \\
\text { 2019 }\end{array}$ & $\begin{array}{c}\text { Cases: } \\
\text { SA/GA-2020 }\end{array}$ & $\begin{array}{c}p \text { - } \\
\text { value }\end{array}$ \\
\hline Specialty & $\begin{array}{c}100(55.5 \%) / 80 \\
(44.4 \%)\end{array}$ & $\begin{array}{c}18(78.2 \%) / 5 \\
(21.7 \%)\end{array}$ & 0.007 \\
\hline $\begin{array}{l}\text { General } \\
\text { surgery }\end{array}$ & $\begin{array}{c}40 \%) / 10 \\
(20 \%)\end{array}$ & $\begin{array}{c}40(93 \%) / 3 \\
(6.9 \%)\end{array}$ & 0.001 \\
\hline Gynaecology & $\begin{array}{c}14(46.6 \%) / 16 \\
(53.3 \%)\end{array}$ & $\begin{array}{c}19(82.6 \%) / 4 \\
(17.3 \%)\end{array}$ & 0.002 \\
\hline Orthopedics
\end{tabular}

Table-III: List of emergency cases of different specialties.

\begin{tabular}{l|l|c}
\hline Specialty & $\begin{array}{l}\text { Emergency Surgical } \\
\text { procedures }\end{array}$ & $\mathbf{n}(\mathbf{\%})$ \\
\hline \multirow{5}{*}{ General } & Appendectomy & $15(65.2)$ \\
surgery & Obstructive hernia repair & $2(8.6)$ \\
& hemorrhoidectomy & $1(4.3)$ \\
& Ray amputation & $1(4.3)$ \\
& Burn debridement & $2(8.6)$ \\
& Incision \& Drainage Hand & $2(8.6)$ \\
\hline \multirow{5}{*}{ Gynaecology } & Caesarean section & $37(86)$ \\
& Laparotomy & $3(6.9)$ \\
& Dilatation \& Curettage & $3(6.9)$ \\
\hline \multirow{5}{*}{ Orthopedics } & Open reduction \& Internal & \\
& fixation (ORIF) femur & $11(47.8)$ \\
& Dynamic hip screw (DHS) & $3(13)$ \\
& ORIF Ankle & $2(8.6)$ \\
& Intramedullary nailing (I/M) & $3(13)$ \\
& Tibia & $2(8.6)$ \\
& ORIF elbow & $2(8.6)$ \\
\hline
\end{tabular}

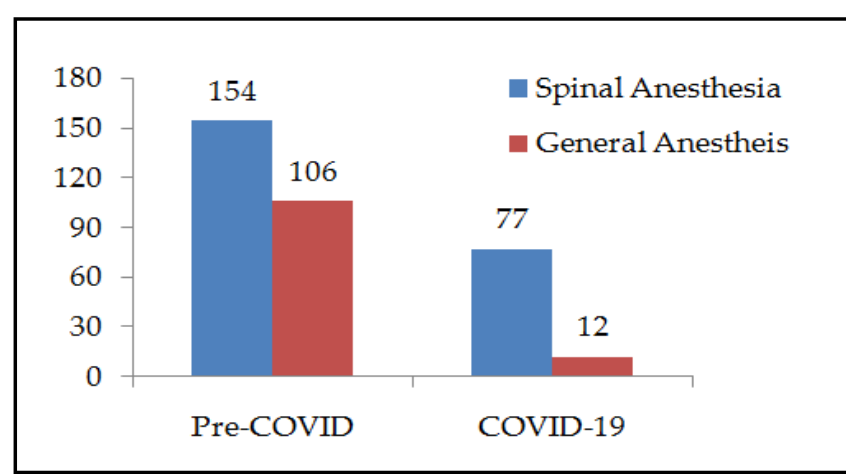

Figure: Comparison of spinal versus general anesthesia cases in pre-COVID and COVID-19 period. 


\section{DISCUSSION}

Proper planning is essential to prevent from COVID-19 and other infections peri-operatively. Risks are mostly associated with endotracheal procedures. In order to decrease the risks of transmission, intubation requirement must be justified in patients with respiratory failure and on noninvasive ventilation (e.g., CPAP or BiPAP) preference should be given to disposable airway equipment. Operation theatre staff must be equipped with FFP3 filters in all aerosol generating procedures. Negative pressure operation theatres are considered to be ideal to minimize the infection risk. However, operation theatres are normally designed to have positive pressure air circulation. A high air exchange cycle rate $(\geq 25$ cycles $/ \mathrm{h})$ contributes to effectively reduce the viral load within operation theatres ${ }^{11}$.

According to European and American Societies of Regional Anaesthesia, regional anaesthesia should be preferred over general anaesthesia, during COVID19. The Royal College of Anaesthetists, also recommends local or regional anaesthesia where required, in order to preserve emergency drugs, during the critical care of COVID-19 patients ${ }^{12}$. Other benefits of giving regional anaesthesia during the COVID-19 pandemic may include: more reserve of PPE, better postoperative analgesia and earlier discharge. Advantages such as less postoperative complications, less time in recovery and early discharge are particularly valuable. Avoidance of general anesthesia in COVID-19 patients, undergoing emergency surgery is seems to be beneficial, but mortality rates of patients with undiagnosed COVID-19 who subsequently undergo surgery is higher and therefore significant reduction in cases occurred. According to the data of operation theatres in Italy, $86 \%$ decrease of cases of emergency surgery occurred as compared to the corresponding month before the COVID-1913.

More studies are required to make evidencebased recommendations for the prevention of perioperative COVID-19 infection. However, the safest approach to avoid SARS-CoV-2 transmission may be the one that reduces operation time and is the most familiar to the operation team. Urgent surgical cases are classified into high and low-risk procedures, depending upon the anticipated viral load at the surgical area and the risk that a procedure may cause aerosolization of virus ${ }^{14}$. Regional Anaesthesia is preferred over general anesthesia in emergency cases to reduce the risk of aerosolization, usually related to endotracheal intubation. Guidelines for donning of PPE for AGP should be practiced for emergency surgeries due to the risk of failed regional anesthesia and the consequent conversion to general anaesthesia. The main risk of general anaesthesia in caesarean section is getting infection due to endotracheal intubation in patients with acute respiratory illness. Endotracheal intubation is AGP and the risk of transmission of virus to staff is higher than with non-AGP. Guidelines to reduce the risk must be followed. Checklists, standardized emergency airway trolleys can improve outcomes. Extubation is equally high-risk AGP. By reducing number of staff in the operating room and avoidance of cough at the time of extubation, risk can be minimized ${ }^{15}$. Regional anesthesia is preferred during delivery of COVID19 patients, because these techniques reduce the cardiopulmonary stress, caused by stress of labor, as according to a case report by Bampoe et al, A 29-year-old woman, G2P1 at $37 \pm 4$ weeks of gestation, COVID-19 positive, symptomatic, received spinal anesthesia for emergency caesarean section and was found successful with early post-operative recovery. Moreover, as spinal anesthesia is not considered as AGP, has benefit over general anesthesia, in maintaining personal protective equipment reserves ${ }^{16}$. Zhong et al, found that out of $44,37(84.1 \%)$ patients were provided regional anaesthesia by using Level 3 PPE, 1 (2.7\%) of 37 anaesthetists who used PPE level 3, developed COVID-19 infection as compared to $4 / 7$ (57.1\%) anaesthetists who had Level 1 protection in the operating room (relative risk reduction: $95.3 \%$ [95\% confidence intervals: $63.7-$ 99.4]; $p<0.01$ ) and COVID-19 infection was subsequently confirmed by PCR in 5/44 (11.4\%) anaesthetists ${ }^{17}$. Warren et al, demonstrated multivariate regression analysis of the total hip arthroplasty cohort and showed a statistically not significant trend toward increased mortality in GA patients (OR, 1,433; 95\% confidence interval $[\mathrm{CI}], 0.988$ to $2.078 ; p=0.058$ ) as compared to SA patients, also found that GA cohort were at higher risk for complications $(p<0.05)$ and patients who received GA were at higher risk for nonhome discharge $^{18}$. A total of 338 emergency surgical cases were performed during the COVID-19 pandemic in 2020, compared to 603 cases over the corresponding period in 2019. This showed a $44 \%$ decrease in emergency surgical workload. The use of RA as the primary anesthesia technique was noticeably higher than previous UK data $(11 \%)$, and was prominent in specialties such as general surgery, gynecology and urology, not traditionally completed under RA ${ }^{19}$.

Endotracheal intubation is a high-risk procedure, due to the risk of spread of droplets and aerosols. That's why airway management needs special atten- 
tion, and endotracheal intubation ideally should be undertaken in an airborne isolation room and all concerned health care provider should be equipped with airborne/droplet prevention PPE. According to one of the study of China, 202 COVID-19 patients in Wuhan, requiring urgent endotracheal intubation, personal protective equipment used as per recommendations for aerosol generating procedures and technique also based on rapid sequence induction (RSI) and videolaryngoscopy, which enabled prompt tracheal intubation and was universally successful ${ }^{20,21}$.

\section{LIMITATION OF STUDY}

Data from other hospitals should also be gathered but due to risk of spreading of infection due to handling with papers, it wouldn't possible.

\section{CONCLUSION}

Spinal anesthesia has a significant role in the surgical management of patients in pre-COVID and especially in COVID pandemic. It provides high-quality perioperative care for patients whilst minimizing exposure to staff and utilization of scarce resources of PPE.

\section{CONFLICT OF INTEREST}

This study has no conflict of interest to be declared by any author.

\section{REFERENCES}

1. Aminnejad $R$, Shafiee $H$. Is Regional anesthesia safe enough in suspected or confirmed COVID-19 patients. ACS Chem Neurosci 2020; 11(9): 1371-71.

2. Uppal V, Sondekoppam RV, Landau R, El-Boghdadly K, Narouze S, Kalagara HK. Neuraxial anaesthesia and peripheral nerve blocks during the COVID-19 pandemic: a literature review and practice recommendations. Anaesth Anaesth 2020; 75(10): 1350-63.

3. El-Boghdadly K, Wong DJ, Owen R, Neuman MD, Pocock S, Carlisle JB, et al. Risks to healthcare workers following tracheal intubation of patients with COVID-19: a prospective international multicentre cohort study. Anaesth Inten Care 2020; 75(11): 1437-47.

4. Kim HJ, Ko JS, Kim TY. Recommendations for anesthesia in patients suspected of COVID-19 Coronavirus infection. Korean J Anesthesiol 2020; 73(2): 89-91.

5. Zuo M, Huang Y, Ma W, Xue Z, Zhang J, Gong Y et al. Expert Recommendations for tracheal intubation in critically III patients with noval coronavirus disease 2019. Proc Chin Acad Med Sci Peking Union Med Coll 2020; 35(2): 105-109.

6. Lockhart SL, Duggan LV, Wax RS, Saad S, Grocott HP. Personal protective equipment (PPE) for both anesthesiologists and other airway managers: principles and practice during the COVID-19 pandemic. Can J Anaesth 2020; 67(8): 1005-15.
7. De Simone B, Chouillard E, Di Saverio S, Pagani L, Sartelli M, Biffl WL. Emergency surgery during the COVID-19 pandemic: what you need to know for practice. Ann R Coll Surg Engl 2020; 102(5): 323-32.

8. Weissman DN, De Perio MA, Radonovich LJ. COVID-19 and risks posed to personnel during endotracheal intubation. JAMA 2020; 323(20): 2027-28.

9. Tan L, Kovoor JG, Williamson P, Tivey DR, Babidge WJ, Collinson TG, et al. Personal protective equipment and evidence based advice for surgical departments during COVID-19. ANZ J Surg 2020; 90(9): 1566-72.

10. Chen X, Liu Y, Gong Y, Guo X, Zuo M, Li J, et al. Perioperative management of patients infected with the novel coronavirus: recommendation from the Joint Task Force of the Chinese Society of Anesthesiology and the Chinese Association of Anesthesiologists. Open J Anesthesiol 2020; 132(6): 1307-16.

11. Coccolini F, Perrone G, Chiarugi M, Di Marzo F, Ansaloni L, Scandroglio I, et al. Surgery in COVID-19 patients: operational directives. World J Emerg Surg 2020; 15(25): 1-7.

12. Macfarlane AJ, Harrop-Griffiths W, Pawa A. Regional anaesthesia and COVID-19: first choice at last?. Br J Anaesth 2020; 125(3): 243-47.

13. Patriti A, Eugeni E, Guerra F. What happened to surgical emergencies in the era of COVID-19 outbreak? Considerations of surgeons working in an Italian COVID-19 red zone. Updates Surg 2020; 72(2): 309-10.

14. Zhao S, Ling K, Yan H, Zhong L, Peng X. Anesthetic management of patients with COVID 19 infections during emergency procedures. J Cardiothorac Vasc Anesth 2020; 34(5): 1125-31.

15. Bampoe S, Odor PM, Lucas DN. Novel coronavirus SARS-CoV-2 and COVID-19. Practice recommendations for obstetric anaesthesia: what we have learned thus far. Int J Obstet Anesth 2020; 43(4): $1-8$.

16. Hani DA, Alsharaydeh I, Bataineh AM, Al Athamneh M, Qamileh I, Al-Baik A, et al. Successful anesthetic management in cesarean section for pregnant woman with COVID-19. Am J Med Case Rep 2020; 21(1): e925512-18.

17. Zhong Q, Liu YY, Luo Q, Zou YF, Jiang HX, Li H, et al. Spinal anaesthesia for patients with coronavirus disease 2019 and possible transmission rates in anaesthetists: retrospective, single-centre, observational cohort study. Br J Anaesth 2020; 124(6): 670-75.

18. Warren J, Sundaram K, Anis H, Kamath AF, Mont MA, Higuera $\mathrm{CA}$, et al. Spinal anesthesia is associated with decreased complications after total knee and hip arthroplasty. J Am Acad Orthop Surg 2020; 28(5): e213-21.

19. Wade S, Nair G, Ayeni HA, Pawa A. A cohort study of emergency surgery caseload and regional anesthesia provision at a tertiary UK hospital during the initial COVID-19 pandemic. Cureus 2020; 12(6): 1-5.

20. Yao W, Wang T, Jiang B, Gao F, Wang L, Zheng H, et al. Emergency tracheal intubation in 202 patients with COVID-19 in Wuhan, China: lessons learnt and international expert recommendations. Br J of Anaesth 2020; 125(1): e28-37.

21. Brewster DJ, Chrimes NC, Do TB, Fraser K, Groombridge CJ, Higgs A, et al. Consensus statement: safe airway society principles of airway management and tracheal intubation specific to the COVID-19 adult patient group. Med J Aust 2020; 212(10): $472-81$. 